\title{
The effect of the eccentric loading on the components of the spine
}

\author{
Samir Zahaf ${ }^{*}$, Bensamine Mansouri ${ }^{1}$, Abderrahmane Belarbi ${ }^{1}$ and Zitouni Azari $^{2}$ \\ ${ }^{1}$ Department of Mechanical Engineering, University of Sciences and Technology, Oran, Algeria \\ ${ }^{2}$ Laboratory of Biomechanics, Polymers and Structures, ENIM-Metz, France
}

\begin{abstract}
The objective of this work is to study the effect of the backpack on the components of the spine system of a child, know the effect of an eccentric load on the intervertebral discs, the creating a 3D model of the spine of child of $80 \mathrm{~kg}$ overall weight under the effect of three eccentric load (P2, P3, P4) plus P1 compression load and calculated by the element method ends, For the boundary conditions we fixed the sacrum (Embedding the sacrum). We propose in this section to draw up a comprehensive study of the distributions of stresses and normal elastic strain of Von Mises in the intervertebral discs based on loads supported. The results show that the stress and strain of Von Mises are highest and concentrated in four intervertebral discs (D1, D15, D16 and D17), which causes a problem that calls (herniated disc). We concluded that the cause of the posterior load, a $350 \mathrm{~mm}$ lever arm with a 200N load present maximum Von Mises stresses concentrated in four intervertebral discs (D1,D15,D16,D17), which justifies the distance between the load which is the point of application of the load and the axis of the spine plays a very important role in increasing the solicitation of the latter.
\end{abstract}

\begin{abstract}
Abbreviations: $\mathrm{D}_{4}$ : intervertebral disk upstairs four; $\mathrm{N}_{4}$ : nucleus in the intervertebral disc upstairs four; $\mathrm{D}_{2}$ : intervertebral disk upstairs two; $\mathrm{N}_{2}$ : nucleus in the intervertebral disc upstairs two; $\mathrm{L}_{2}$ : lumbar vertebra is on level two; $\mathrm{D}_{4}$ : intervertebral disk upstairs four; $\mathrm{N}_{4}$ : nucleus in the intervertebral disc upstairs four; AF1: annulus fibrosus one; AF2: annulus fibrosus two.
\end{abstract}

\section{Introduction}

The spine or rachis consists of a movable column of 24 free vertebrae and a fixed column formed of fused vertebrae: the sacrum and coccyx; it is the fixing strut of many essential muscles in the posture and locomotion and protects the spinal cord located in the vertebral canal; it supports the head and transmits the weight of the body to the hip joints; with a length of about $70 \mathrm{~cm}$ in men $(60 \mathrm{~cm}$ in women), its reduction may reach $2 \mathrm{~cm}$ when standing [1].

Intervertebral discs connect the vertebral bodies, provide the mobility of the column and amortize them pressure and shocks. Each consisting of a peripheral annulus (annulus) containing a gelatinous core (nucleus). Disc degeneration begins, after a phase of asymptomatic dehydration, with tears in the fibrous ring. The core can then migrate into the thickness of the ring and cause acute or chronic back pain. If it moves further through the ring, the ring may protrude to the rear side of the disc while forming a HERNIATED DISC this is indicated in figure 1 and figure 2. This hernia can migrate into the spinal canal and even exclur leaving the disc. This disc herniation can come compress or "stuck" in one or more nerve roots located near the drive. It is the cause of symptoms: pain is sciatica when the back of the thigh, cruralgie when the pain is in front of the thigh [2] (Figure 1 and 2).

It is the cause of symptoms when sciatic pain is in back of the thigh, crural when pain is in front of the thigh. It comprises variably pain in the lower limbs, defourmillements or tingling sensation (paraesthesia), the sensitivity to disturbance of sensation (dysesthesia) up to a complete loss of feeling (anesthesia), loss muscle strength or partial or complete paralysis or sphincter disorders. continuously exerted, the pressure of the herniated disc can cause irreversible damage.

Every year it is the same finding, schoolchildren satchels or bags to back are too heavy and can cause long-term back problems and deformities of the spine that is to say students complain of back pain, shoulder pain, muscle pain, knee pain, pain in the neck, numbness pain, bad posture, poor balance and falls due at the port of a backpack overloaded view figure 3 [5].

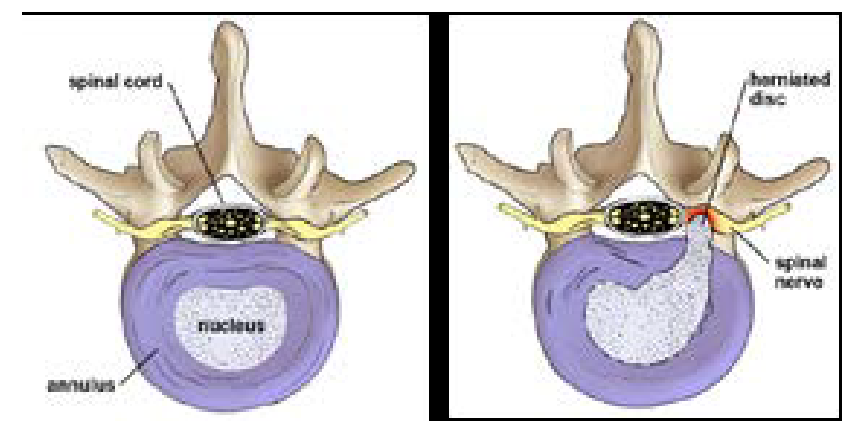

Figure 1. Normal disc (top). Herniated disc (bottom) shows the gel-filled nucleus escapes through a tear in the disc annulus and compresses the spinal nerve [3].

Correspondence to: Samir Zahaf, Department of Mechanical Engineering, University of Sciences and Technology, Oran, Algeria, Tel: +213 (041)-56 03 27; E-mail: zahafsamir1983@gmail.com

Key words: child, herniated discs, lumbar-thoracic, intervertebral discs, finite element, biomechanics, von mises stress-strain, disc degeneration

Received: October 12, 2016; Accepted: November 23, 2016; Published: November 28, 2016 


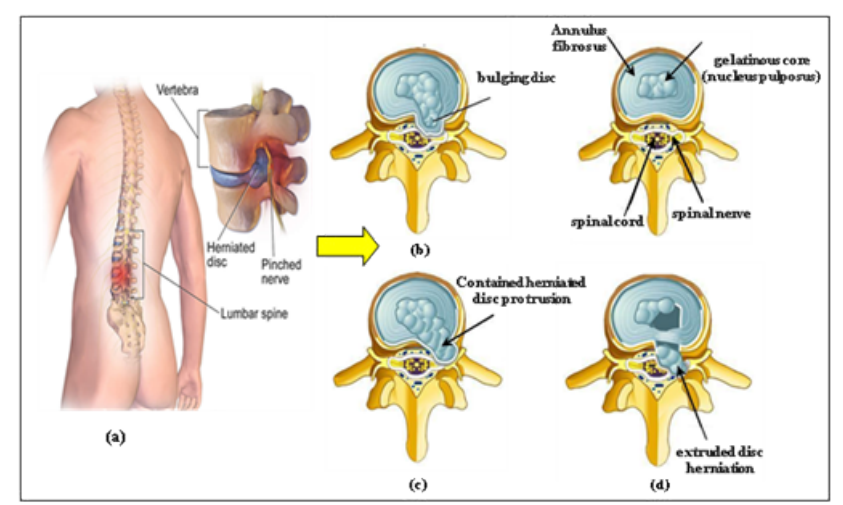

Figure 2. Evolutionary forms of the herniated disc. (a) Back pain. (b) Crack the annulus, (c) Progression the disc material, (d)Prolapse [4].

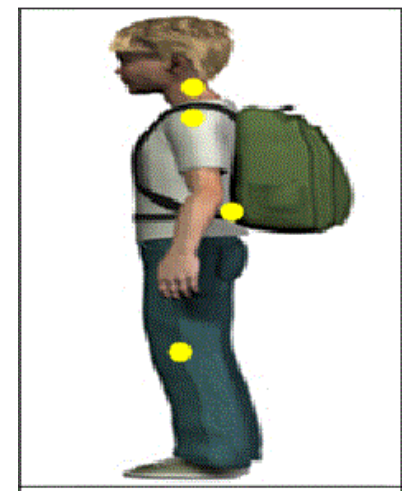

Figure 3. A school child wears a backpack.

Worse, their weight increases over the years from $6.5 \mathrm{~kg}$ in 1997 to $8 \mathrm{~kg}$ today in the best case. This would amount to carry to an adult of $80 \mathrm{~kg}$ weight $17 \mathrm{~kg}$ Yet the official circular of 2008 National Education clearly advocates that the weight of the backpack should not exceed $10 \%$ of the weight of the child, ie, primary, about $2.5 \mathrm{~kg}$... we're off!! It is between 8 and 15 years back is the most fragile, and scientific studies have demonstrated imaging (MRI), the risk of joint damage and intervertebral disc are real [5].

Yet the official circular of 2008 National Education clearly advocates that the weight of the backpack should not exceed $10 \%$ of the weight of the child, either primary, about $2.5 \mathrm{~kg}$... we're off!! It is between 8 and 15 years back is the most fragile, and scientific studies have demonstrated imaging (MRI), the risk of joint damage and intervertebral disc are real [5].

During this period of school age, the spine of children is particularly rough ride. With their school bags too heavy, students are real porter, causing stiffness and pain, which are themselves a source of bad posture on often inadequate seating.

It is in this context daily, as well as family education, the accumulation, repetition of these situations will cause joint damage, common causes such as scoliosis. This explains the fact that $67 \%$ of students suffer from muscle tension, $50 \%$ of back pain, $24 \%$ falling asleep during classes and $15 \%$ of pain in the shoulders [5]. The schoolbag defined as an eccentric load figure 3 the load represented by the mass (P4), in other words, this load created a moment of posterior bending which tends to bend the spine and causes a problem called lumbar disc herniation is the most common cause of low back pain.
The diagram figure 4 represents a child to age 10 years of overall specific weight $38 \mathrm{~kg}$ to wear a backpack, backpack is the mass of $15 \mathrm{~kg}$ representing the weight $\mathrm{P} 4$.

The MRI study [6], alerts of this overweight effect in the development of degenerative disc disease, back pain and then herniated disc (Figure 5).

In this work, the simulation of the disc degeneration, based on a finite element model of the spine depending on the mechanical properties were established; the boundary condition has been applied in the frontal plane to define restriction on movements of translation and rotation of the spine.

We propose in this work to draw up a comprehensive study of stresses and strains in the spinal discs distributions based on supported loads. The results show that the level of degeneration increased in all intervertebral discs but concentrated in the four disks D1, D15, D16 and D17.

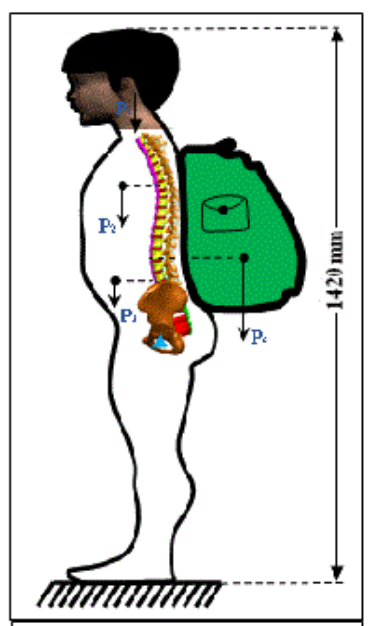

Figure 4. Model biomechanics of the spine (A school child wears a backpack).

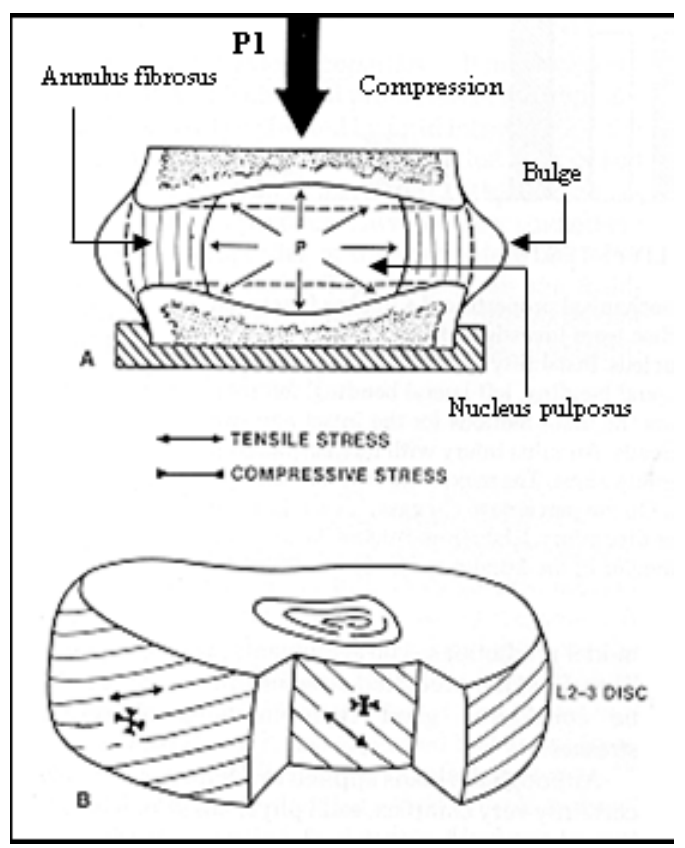

Figure 5. The intervertebral disc with (a): compression [7]. 
Figure 5 shows two vertebrae of the spinal column with an intervertebral disc under the effect of a compound loading (compression $\mathrm{P} 1+$ bending moment P4). The compressive load P1 creates an internal pressure in the nucleus, this pressure will there after generate the disc degeneration or degenerative disc disease (Figure 5-7) as regards the forward flexion P4, if the load of the schoolbag increases, automatically distance between the point of load application and the axis of the spinal column increases, we see that the posterior portion of the annulus fibrosis is compressed and the other front portion is tensioned, that is to say the nucleus pulposus burst back (posterior compression), this compression produced by disc protrusion comes into contact with a nerve root called herniated disc this mentioned in Figure 2.

\section{Material and methods}

The objective of this study was to investigate the effects induced by an eccentric load of the backpack on the back of a child, know the effect of an eccentric load on the intervertebral discs, cortical bone, cancellous bone, posterior bone, sacrum, basin, created a 3D model of spine, the total mass of person standing of specific global $80 \mathrm{~kg}$ under the effect

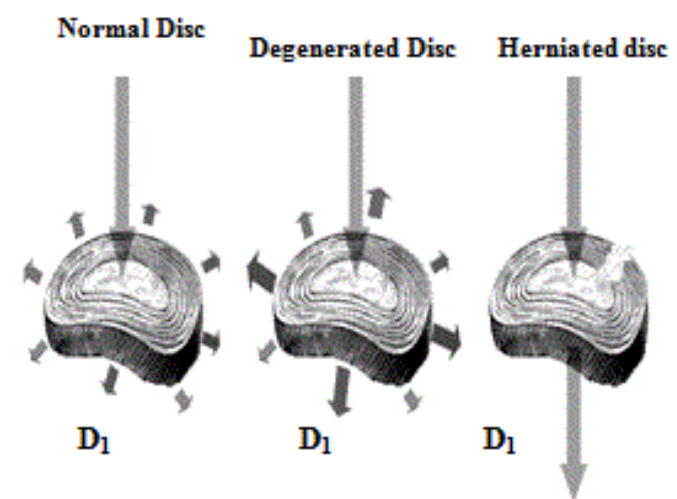

Figure 6. Load distribution at the disc D1 according to his state [8].

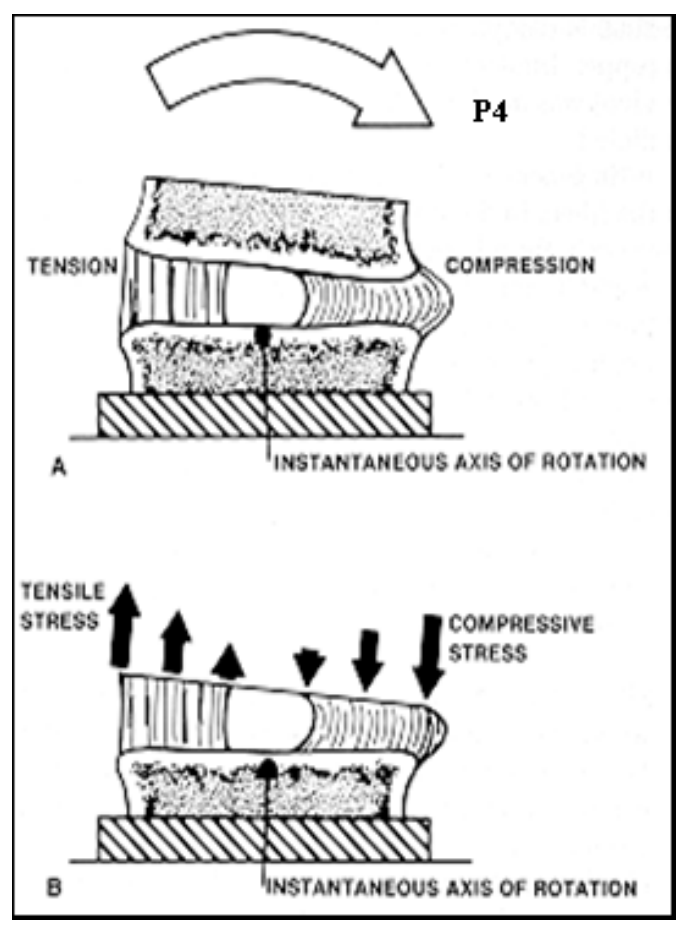

Figure 7. The intervertebral disc with (b): bending [7] of three eccentric loads (p2, p3, p4) plus a p1 compression load and calculated by the finit element method, the boundary conditions we fixed the sacrum (incorporation of the sacrum) (Figure 4).

The analysis of biomechanical problems includes several steps.

The first is to study the form to define the geometrical configuration of the object, which allows the reconstitution of the vertebra, the ligament and bone using CAD programs.

The result is a 3D geometric model including these three components will then be prepared for use in finite element analyzes for the study of stresses and strains distribution in the system.

The steps for the execution of the $3 \mathrm{D}$ vertebra model figure 8 are as follow:

a) Draw cortical bone that is the upper hinge and the lower hinge, then make the smoothing process; this gives a solid body called the vertebral body.

b) Secondly, draw the posterior arch (blade with the pedicle) with the spinous process.

c) Finally we draw the transverse process.

The simulation of the disc degeneration is based on a finite element model of the healthy spine. Figure 9 shows a spine model, this consists of five lumbar vertebrae (L1, L2, L3, L4 and L5) plus the sacrum and the basin, twelve thoracic vertebrae (TH1, TH2, TH3, TH4, TH5, TH6, TH7, TH8, TH9, TH10, TH11, TH12) and 17 inter vertebral discs between (S1-L5, L5-L4, L4-L3, L3-L2, L2-L1, L1-TH12 TH12-
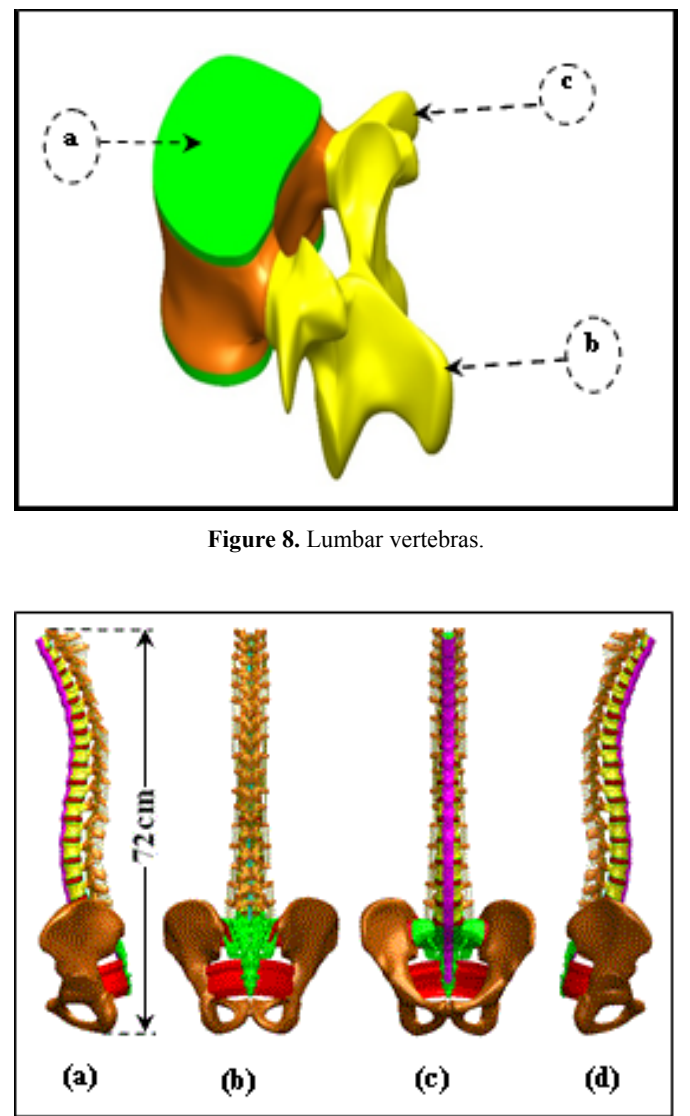

Figure 9. Spine studied (a): Lateral (left) view (b): dorsal view (c): front view. (d): lateral (right) view. 
TH11, TH11, TH10, TH10-TH9, TH9-TH8, TH8-TH7, TH7-TH6, TH6-TH5, TH5-TH4, TH3-TH4, TH3-TH2 TH2-TH1) and various ligaments thoracic lumbar spine (anterior longitudinal ligament, posterior longitudinal ligament, ligament interspinous, ligament supraspinatus, yellow ligament and capsular ligament), ligaments of the basin (sacroiliac posterior ligament, sacrotuberous ligament and interosseous ligament).

In static loading conditions, the model of the reconstructed spine is used in an analysis for studying the role of the inter vertebral discs and the stress distribution in these disks as well as its supporting structures. The spine is reconstructed in $3 \mathrm{D}$ to study the system dimensions (IVD - ligament-bone) (Figure 10).

In order to define the boundary conditions, restriction on movements of translation and rotation of the spine has been applied in the lower plane, and defined as having zero displacements. Several charges in the anterior direction were applied as follows:

- The application of the load on the upper side of the thoracic vertebra TH1.

- The fixed part applied to the body of the basin.

- The interfaces between the different components of the system of the spine, the cortical bone, the inter vertebral disk and ligament are treated as perfectly bonded interfaces figure 10 .

Figure 9 shows an isometric view of an explored assembly of the spine and each component of the spine system is denoted by letters.

The selection of constitutive equations of the vertebral bone is defined as the part of the bone which carries the inter vertebral disc, composed of cortical bone, cancellous bone, the posterior arch, with a Young's modulus of about $12000 \mathrm{MPa}$. It is well known that cortical
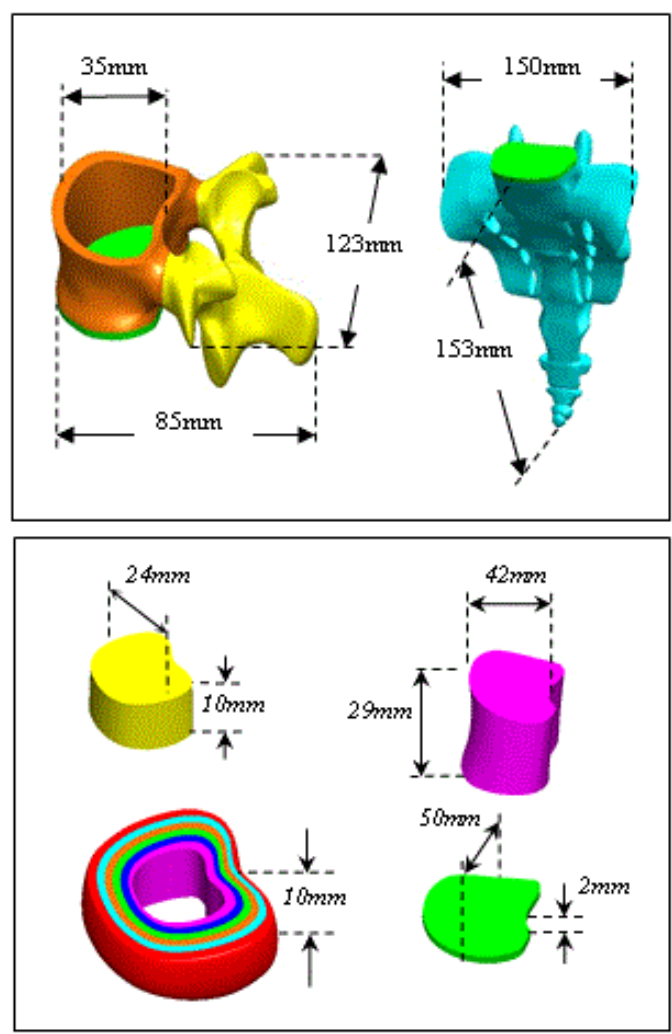

Figure 10. Vertebra and sacrum dimensions. bone has better load capacity than the cancellous bone. Cortical bone is considered as an isotropic material, and homogeneous linear elastic. Table 1 shows the tensile strength of the structure annulus fibrosis according to different authors. These materials are anisotropic and non-linear elastic.

The behavior of inter-transverse ligament and inter-spinous ligament is nonlinear viscoelastic as in previous studies [10]; a linear elastic model is chosen to represent this behavior (Figures 11 and 12).

ANSYS WORKBENCH software was used for analyzing this geometry and generate the most suitable mesh. For the studied behavior, we used tetrahedral elements, type Solid187 conforming to defined parametric surfaces interfaces Figure 13.

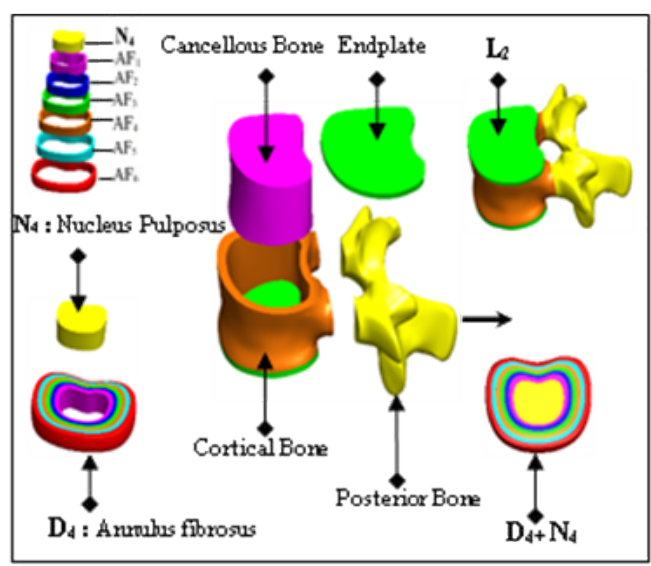

Figure 11. 3D modeling thoracic vertebra L3, D4 disc of the lumbar spine (SOLIDWORKS 2016 software).

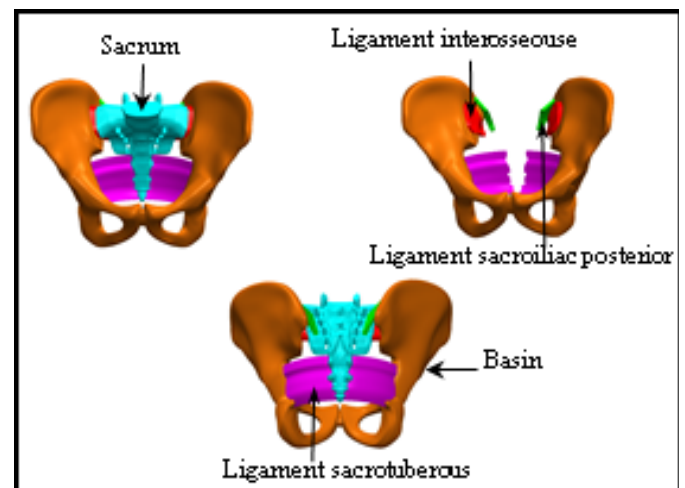

Figure 12. Model details of basin and sacrum (ligaments).

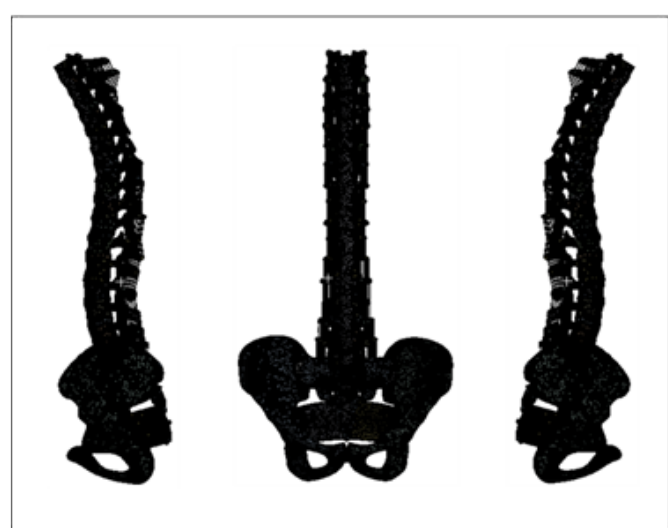

Figure 13. Spine 3D finite element modelling (ANSYS 16.2 software). 
It is necessary to mesh the components of the spine with small and confused elements to ensure optimum accuracy of the results of stresses and strains in the inter vertebral discs.

The material properties of the spine components were selected after a careful review of the published literature Table 2 it was considered appropriate to define the cortical and cancellous bone as homogeneous and isotropic. The magnitudes of $12000 \mathrm{MPa}$ and $100 \mathrm{MPa}$ (cortical and cancellous, respectively) were observed in all studies by various researchers.

Since physiologically the nucleus is fluid filled, the elements were assigned low stiffness values (1MPa) and near incompressibility properties (Poisson's ratio of 0.499). Biologically, the annulus fibrosus is comprised of layers of collagen fibers, which attributes to its nonhomogenous characteristics. However, due to limitations in modeling abilities, the annulus was defined as a homogenous structure with a

Table 1. Mechanical characteristics of disc tissue [9].

\begin{tabular}{|l|c|}
\hline Authors & $\boldsymbol{\sigma}_{\mathbf{r}}(\mathbf{M P a})$ \\
\hline BROWN (axial direction) & 1.4 \\
\hline GALANTE (horizontal direction) & $3.5 \pm 0.3$ \\
\hline GALANTE (fiber direction) & $10.7 \pm 0.9$ \\
\hline WU & 3.7 \\
\hline
\end{tabular}

Table 2. Material Properties Specified in the Model.

\begin{tabular}{|c|c|c|c|}
\hline Material & Young modulus (MPa) & Poisson coefficient & References \\
\hline Cortical Bone & 12000 & 0.3 & {$[11,13,14,15,16,17,18,19,20,21,22,27,36]$} \\
\hline Cancellous Bone & 100 & 0.2 & {$[11,14,15,17,18,19,21,22,24,25,26,27,36]$} \\
\hline Posterior Bone & 3500 & 0.25 & {$[13,14,15,18,19,21,22,24,27,28,37]$} \\
\hline Cartilage Endplates & 12000 & 0.3 & {$[21,23,25,29]$} \\
\hline Annulus Ground Substance & 4.2 & 0.45 & {$[11,14,17,19,20,21,22,23,25,33,31,32,35,36,37]$} \\
\hline Nucleus Pulposus & 1 & 0.499 & {$[12,14,15,16,18,20,21,27,30,33,34,35,36,37]$} \\
\hline Anterior Longitudinal Ligament & 20 & 0.3 & {$[14,15,17,18,19,37]$} \\
\hline Posterior Longitudinal Ligament & 20 & 0.3 & {$[14,15,17,18,37]$} \\
\hline Ligamentum Flavum & 19.5 & 0.3 & {$[14,15,17,18,37]$} \\
\hline Intertransverse Ligament & 58.7 & 0.3 & {$[14,15,17,18,37]$} \\
\hline Inter-Spinous Ligament & 11.6 & 0.3 & {$[14,15,17,18,37]$} \\
\hline Supra-Spinous Ligament & 15 & 0.3 & {$[14,15,17,18,37]$} \\
\hline Capsular Ligament & 32.9 & 0.3 & {$[14,15,17,18,37]$} \\
\hline The basin & & & [38] \\
\hline Sacrotuberous Ligament & 40 & 0.3 & [38] \\
\hline Sacroiliac posterior Ligament & 40 & 0.3 & {$[38]$} \\
\hline Interosseouse Ligament & 40 & 0.3 & [38] \\
\hline
\end{tabular}

Table 3. Element and node numbers in the column vertebral system components.

\begin{tabular}{|c|c|c|c|}
\hline Component & Nodes & Elements & Thickness \\
\hline Cortical Bone & 961810 & 644683 & $3 \mathrm{~mm}$ \\
\hline Cancellous Bone & 244460 & 164441 & $3 \mathrm{~mm}$ \\
\hline Posterior Bone & 226389 & 132464 & $3 \mathrm{~mm}$ \\
\hline Cartilage endplates & 160055 & 87710 & $3 \mathrm{~mm}$ \\
\hline Annulus Ground Substance & 244800 & 114036 & $3 \mathrm{~mm}$ \\
\hline Nucleus Pulposus & 42449 & 26112 & $3 \mathrm{~mm}$ \\
\hline Anterior Longitudinal Ligament & 45798 & 24467 & $3 \mathrm{~mm}$ \\
\hline Posterior Longitudinal Ligament & 14414 & 6607 & $3 \mathrm{~mm}$ \\
\hline Ligamentum Flavum & 30226 & 13447 & $3 \mathrm{~mm}$ \\
\hline Transverse Ligament & 285328 & 131648 & $3 \mathrm{~mm}$ \\
\hline Inter-Spinous Ligament & 28968 & 13158 & $3 \mathrm{~mm}$ \\
\hline Supra-Spinous Ligament & 17833 & 8279 & $3 \mathrm{~mm}$ \\
\hline Capsular ligament & 51816 & 24072 & $3 \mathrm{~mm}$ \\
\hline Sacrotuberous Ligament & 20878 & 10128 & $3 \mathrm{~mm}$ \\
\hline Sacroiliac posterior Ligament & 5876 & 3280 & $3 \mathrm{~mm}$ \\
\hline Interosseouse Ligament & 13756 & 8306 & $3 \mathrm{~mm}$ \\
\hline TOTAL & 2005025 & 1178694 & $3 \mathrm{~mm}$ \\
\hline
\end{tabular}

This was based on the modulus of the ground substance (4.2 MPa) and the collagen fibers reported in the literature, taking into account the volume fraction of each component. The complete model of the spine Figure 13 was realized by the SOLIDWORKS SOFTWARE VERSION 2014 and was then transferred to the software Calculates each element ends ANSYS 16.2 WORKBENCHE generated the default mesh then generated linear global custom mesh tetrahedra 10 nodes conform to surface.

The three views of spine model with condensed mesh are shown in Figure 13. All element and node numbers are specified in Table 3.

Figure 13 shows a complete model that consists of 1178694 elements and 2005025 nodes. Cortical bone contains (644683 elements and 961810 nodes), cancellous bone contains (164441 elements 244460 nodes).

The posterior arch was modeled with tetrahedral elements to 10 nodes contains (132464 elements, 226389 nodes), the nucleus pulposus in the annulus fibrosus were modeled with tetrahedral type elements 10 nodes (26112 elements 42449 nodes), the annulus fibrosus were modeled with elements of type tetrahedral to 10 nodes (114036 elements, 244800 nodes). 


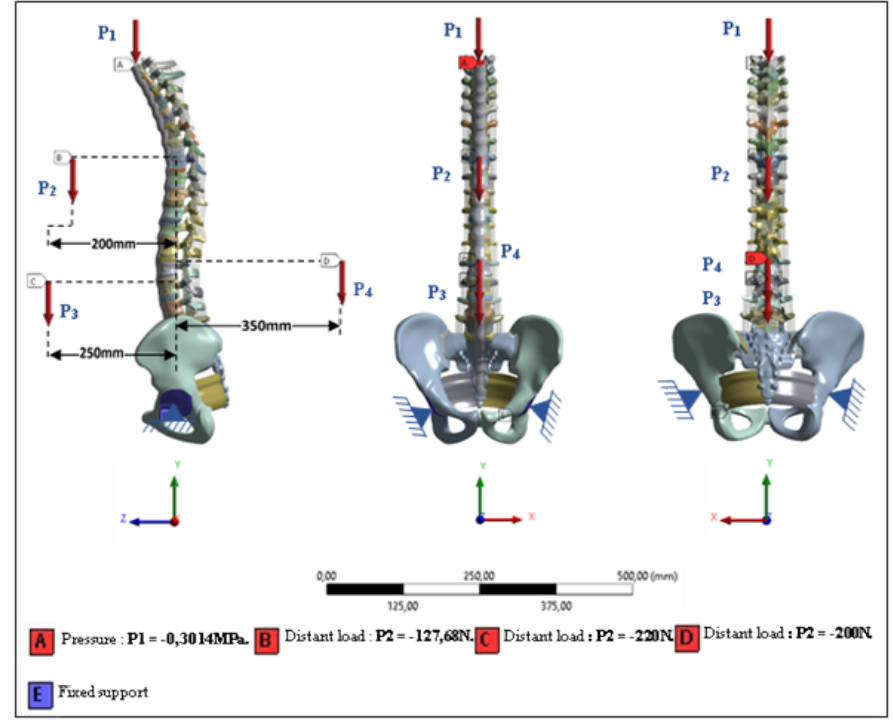

Figure 14. Model biomechanics of the spine (posterior loading).

The gelatinous cartilage modeled with a tetrahedral element to 10 nodes (87710 elements, 160055 nodes). Finally, the different types of ligaments generated by a tetrahedral mesh to 10 nodes Table 3 .

The diagram in figure 4 shows a person standing of specific global $80 \mathrm{~kg}$ weight, the overall mass (Head, Neck, Arm (left + right), Forearm (left + right), hand $($ left + right $))$ is $13,4517 \mathrm{~kg}$ to divided by the top surface of the thoracic vertebrae Th1 representing the pressure P1, P2 load represents the mass of the body superior Trunk is $12,768 \mathrm{~kg}$, the distance between the point of application of the load and axis (yy ") is $200 \mathrm{~mm}$ figure 14.

The total mass of the lower trunk of the human body is equal to 22 $\mathrm{kg}$; represented by $\mathrm{P} 3$, the distance between the point of application of the load and the axis (yy ') is $250 \mathrm{~mm}$ figure $14 \mathrm{P} 4$ represents the maximum mass of the backpack is $(20 \mathrm{~kg})$, the distance between the point of load application and the axis ( $\mathrm{yy}$ ') of the spine is $(350 \mathrm{~mm}$ ) Figure 14.

For the boundary conditions we fixed the sacrum (Embedding the sacrum) Figure 14.

We propose in this section to draw up a comprehensive study of the distributions of stresses and elastic strain in the intervertebral discs, the cortical bone, cancellous bone, the posterior arch, anterior longitudinal ligament and posterior according to the supported loads. Distributions of global stress state for each component of our model were presented.

A quantitative analysis was performed based on a scale of progressive visual colors predefined by the software used (ANSYS Workbench 16.5), ranging from dark blue to red.

\section{Results}

Figure 15 shows a histogram of stress and maximum strain of Von Mises, we notice that the spine undergoes a concentration of maximum stresses in the thoracic region, in the order word the stresses in the thoracic vertebrae (Th3, Th4, Th5, Th6, Th7) are respectively equal to (995,68MPa, 754.61 MPa, 467.09 $\mathrm{MPa}, 483.08 \mathrm{MPa}, 369.65 \mathrm{MPa}$ ) as mentioned in Figure 16.

Figure 17 shows a load applied to the upper surface of the thoracic vertebra TH1 of the spinal column causes a high concentration of
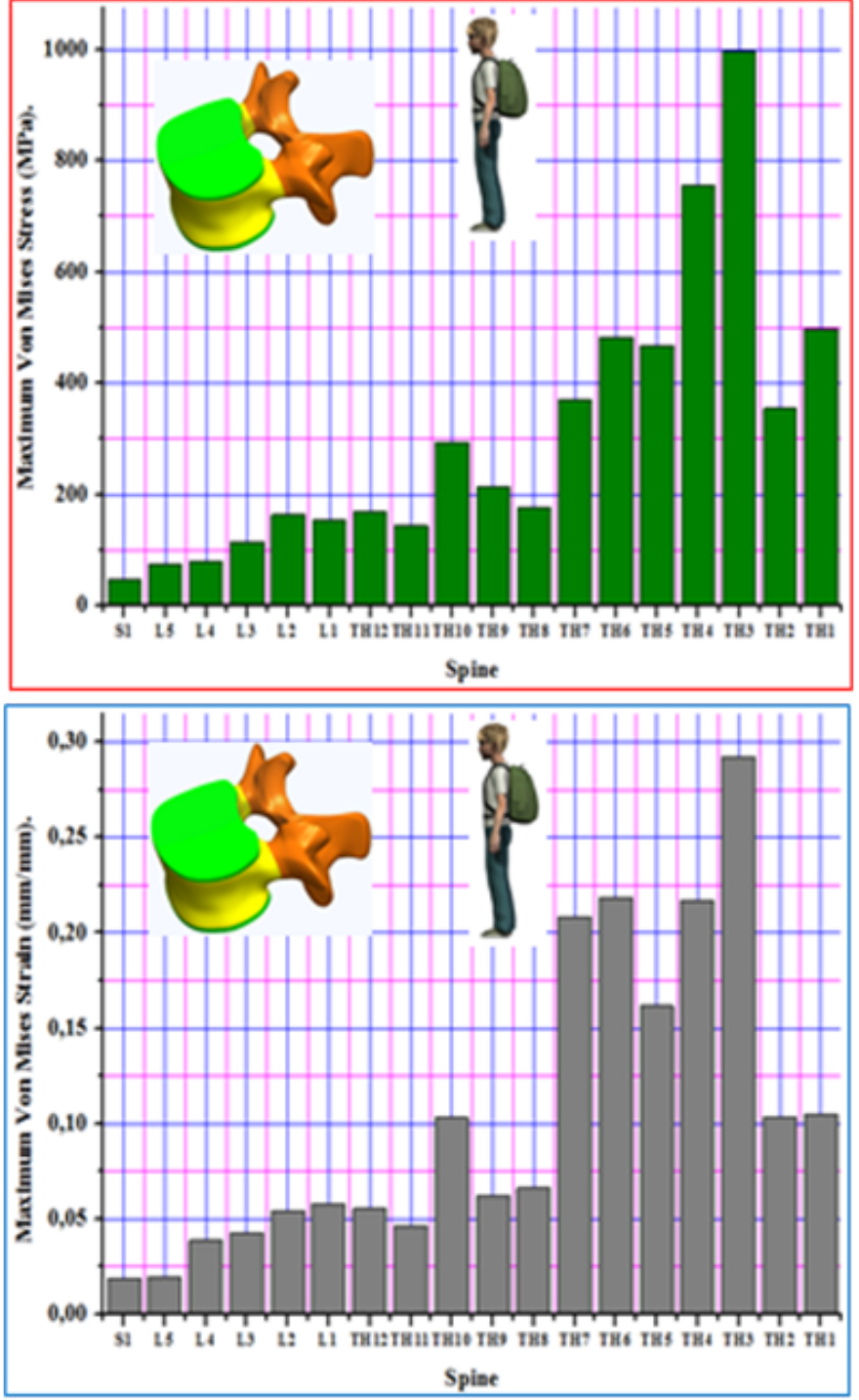

Figure 15. Histogram of stress and strain in the spine for a load of $20 \mathrm{~kg}$

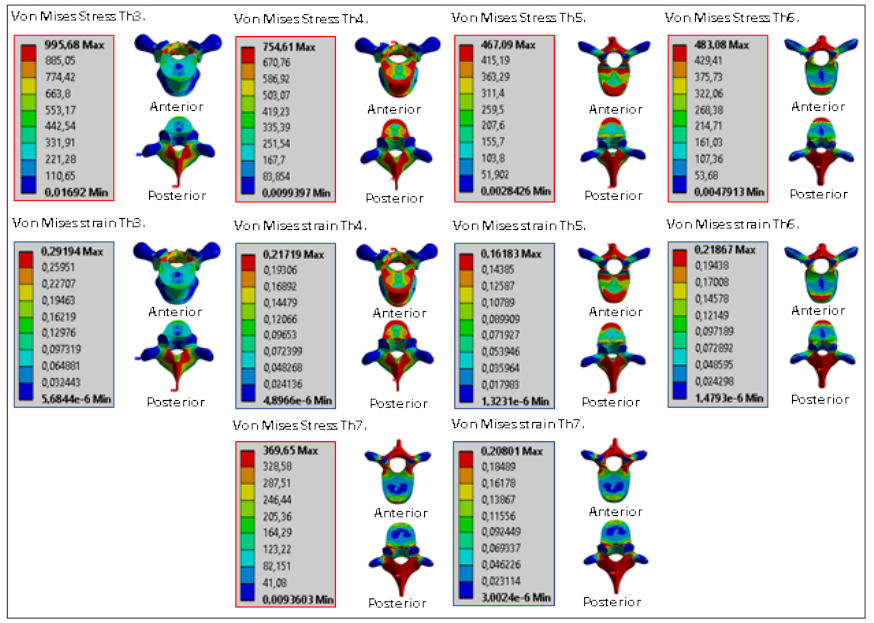

Figure 16. Distributions of stresses and strains in the thoracic vertebrae a load of $20 \mathrm{~kg}$.

maximum Von Mises strains in the anterior part of vertebral bodies (red section) this is mentioned in Figure 17. 
On the other hand, Figure 17 shows that the posterior arch of the thoracic vertebrae (Th3, Th4, Th5, Th6, Th7) absorbed the maximum von Mises stresses, these stresses were observed on a posterior side of the spine (red contour) with respect to other components of the system of the spine. Proceeding from the fact that the Figure 16 and 17 that watches the posterior load presents greater strains within two thoracic vertebrae (Th3, Th4) which are equal to $(0.29194,0.21867)$, which means that the so-called vertebrae are the most stressed in the case of posterior bending.

Figure 18 shows that the posterior loading presents maximum stresses and strains concentrated in the intervertebral disc D1 that is to say between the sacrum and the lumbar vertebra L5, in the order word the figure 19 clearly shows that the loading posterior with a lever arm equal $350 \mathrm{~mm}$ presents maximum Von Mises stresses and strains concentrated in the disc D1 and are respectively equal to $(6,9797 \mathrm{MPa}$, $1,7347 \mathrm{~mm} / \mathrm{mm}$ ).

We see in Figure 18 the intervertebral discs (D1, D15, D16, D17) absorbed the maximum stresses that equal $(6,9797 \mathrm{MPa}, 4,4374 \mathrm{MPa}$,

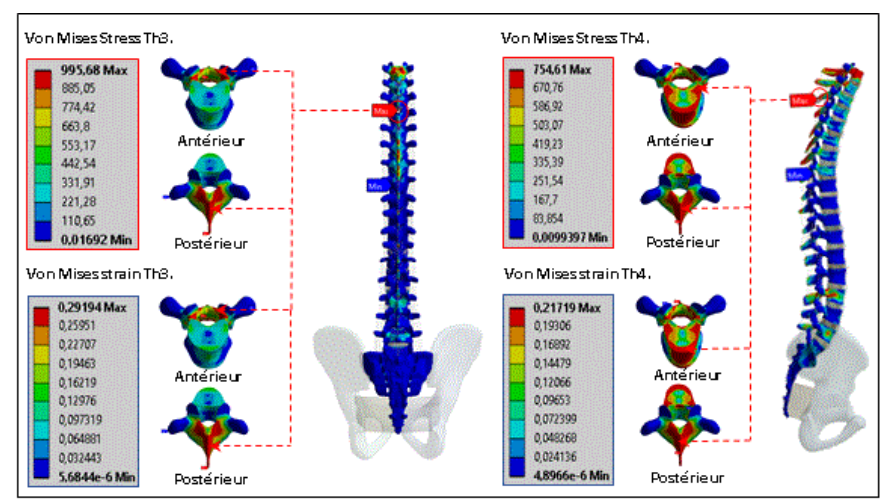

Figure 17. Distributions of stresses and strains in the thoracic vertebrae (Th3, Th4) for a load of $20 \mathrm{~kg}$.
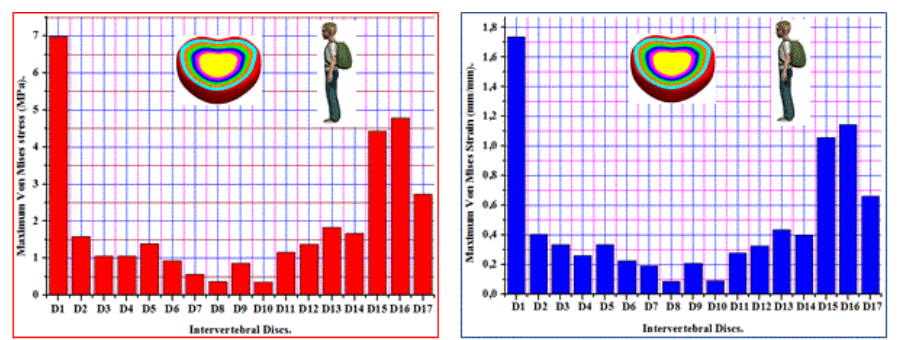

Figure 18. Histogram of stresses and strains in the DIV for a load of $20 \mathrm{~kg}$.

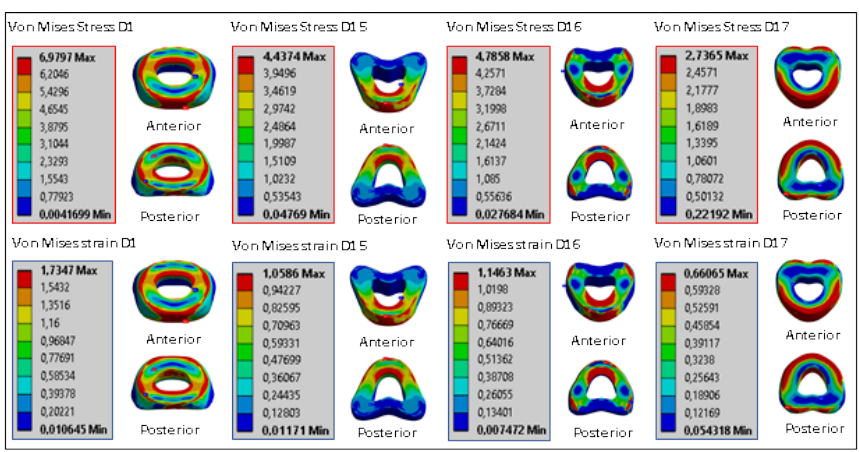

Figure 19. Distributions of stresses and strains in the DIV for a load of $20 \mathrm{~kg}$.
$4,7858 \mathrm{MPa}, 2,7365 \mathrm{MPa})$, On the other hand the posterior loading presents of maximum strains concentrated in the intervertebral discs (D1, D15, D16, D17) which are respectively equal to $(1.7347,1.0586$, $1.1463,0$ 66065) as mentioned in Figure 19. Figure 9 shows that the mixed loading (P1 compression + bending moment (P3)) has a contour of maximum red part stresses in the disc D1 and we see in this figure the front part of the disc D1 is pulled and another compressed part, other hand figure (9) clearly shows that the backpack is a repeated effort back into everyday life ultimately cause disc problems, particularly at the lumbar region (lumbar disc herniation).

Figure 20 shows that the mixed loading ( $\mathrm{P} 1$ compression + bending moment (P3)) has a contour of maximum stresses red part in the disc D1 and we see in this figure the front part of the disc D1 is pulled and another compressed part, other hand figure 20 clearly shows that the backpack is a repeated effort to back into everyday life ultimately cause disc problems, particularly at the lumbar region (lumbar disc herniation).

We see in Figure 21 that the backpack it's a very dangerous loading and with time creates pain in the 1st, 2nd intervertebral disc and causes sciatica or cruralgia, regarding the spinal nerve compressed by the two disks (D1, D2) and the pressure causes intense pain radiating throughout the leg, the path of pain follows closely the path of the nerve. In extreme cases, this results in partial or complete paralysis of the leg.

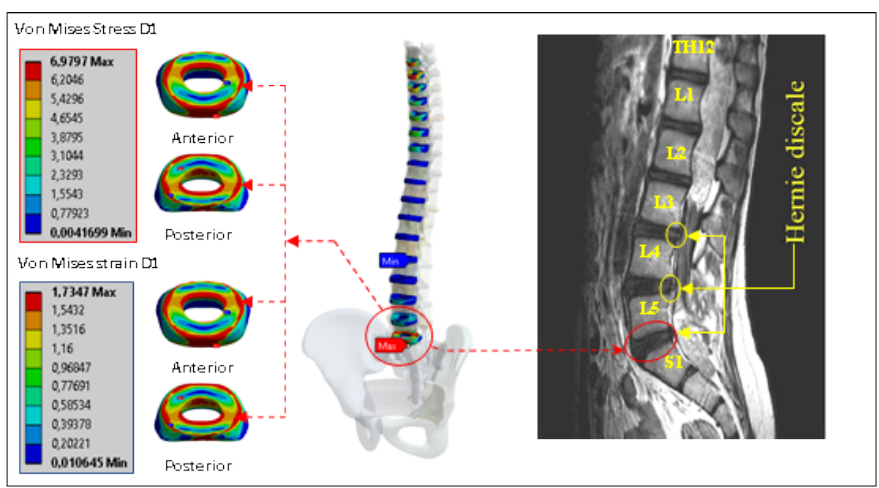

Figure 20. Distributions of stresses and strains in the intervertebral disc D1 for a load of $20 \mathrm{~kg}$.

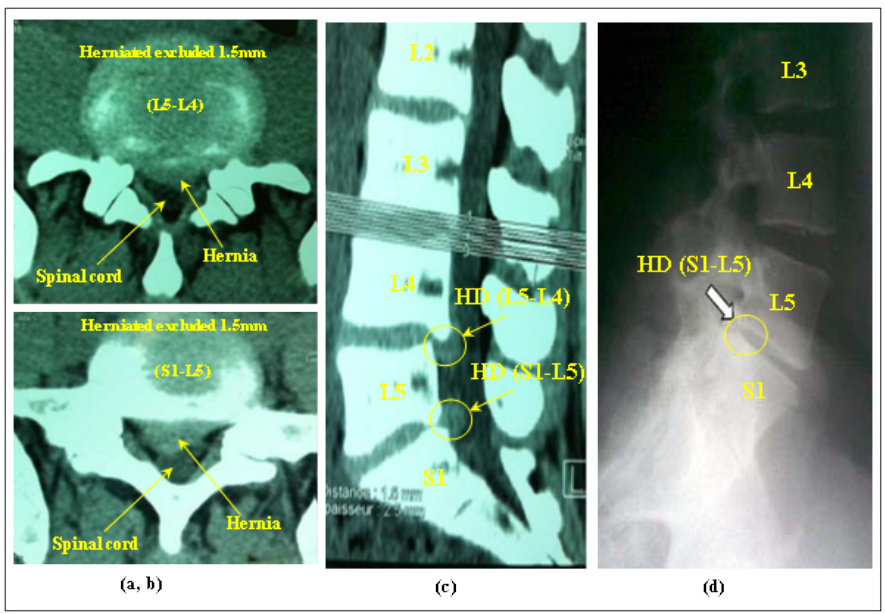

Figure 21. Images of a girl 17 years old suffering back pain so severe, she was unable to walk. TDM spine lumbosacral axial section $(\mathrm{a}, \mathrm{b})$ and sagittal reconstruction (c) showing a double HD L4-L5 and L5-S1 (d) Standard radiography spine profile lumbosacral showing a pinch last intervertebral disc L5-S1. 
A load applied to the upper surface of the thoracic vertebra TH1 of the spinal column causes a high concentration of normal maximum von Mises stresses in the anterior and posterior part of the cortical bone (S1, Th12, Th5, Th1) (parts by red) this is indicated in Figure 22.

On the other hand, figure 23 shows that the maximum von Mises stresses in the cortical bone (S1, Th12, Th5, Th1) are equal to (40,069MPa, 140.15 MPa 223.82 $\mathrm{MPa} 496,69 \mathrm{MPa})$ as compared to other components of the system of the spine see figure 24 .

A loading of the posterior backpack applied on the upper surface of the thoracic vertebra TH1 of the spinal column causes a high concentration of maximum normal strains in the anterior part of the thoracic vertebra Th (red part) this is mentioned in figure 23 with regard to the said vertebra supported Von strain value set which are equal to $(0,041791 \mathrm{~mm} / \mathrm{mm})$ relative to the other components of the system of the spine.

Figure 25 shows a histogram of the stresses and strains Von put supported by the cancellous bone and it is noted that the maximum stress is concentrated in the cancellous bone of the thoracic vertebra Th1 as shown in Figure 26.

The posterior load Figure 3 shows clearly that the stresses and strains of Von Mises are concentrated in the two cancellous bone

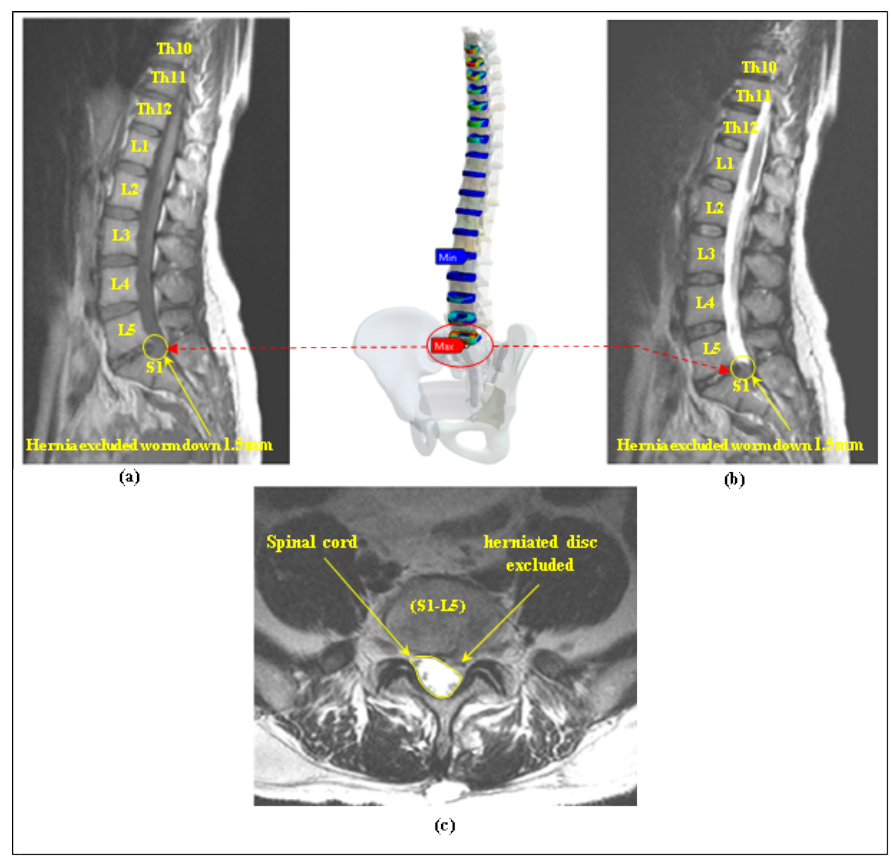

Figure 22. MRI of the lumbar sacral spine of a 16-year-old boy showing: (a) MRI weighted sagittal sequence T1, T2, (b) weighted axial T2, (c) showing a herniated disc L5-S1 posterolateral left side and migrated down.
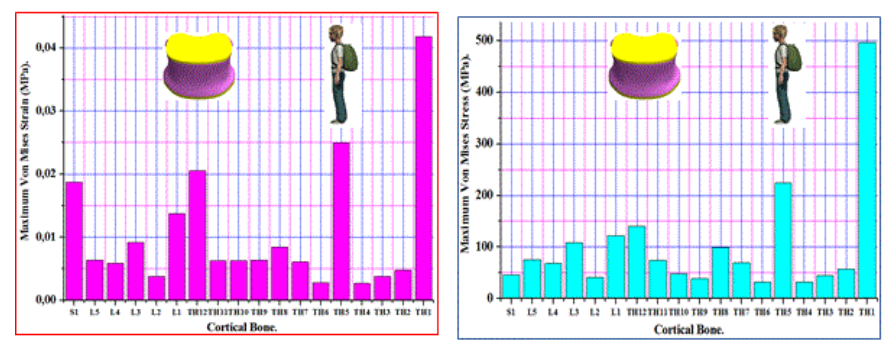

Figure 23. Histogram of stresses and deformations in the cortical bone for load of $20 \mathrm{~kg}$.
(Th1, Th5) and are respectively equal to $(4.6282 \mathrm{Mpa}, 5.7386 \mathrm{MPa})$ and $(0.049594,0.057685)$ this is mentioned in the Figure 26.

The posterior loading of the backpack with a $350 \mathrm{~mm}$ lever shown that increased stresses and strains of Von Mises illustrated in the face of upper and lower articulation of the posterior arch of the thoracic vertebrae (Th3, Th4, Th5 , Th6, Th7) (red outline) Figure 27 on the other hand Figure 28 shows clearly legend stress and strain of Von Mises put in the thoracic region (Th3, Th4, Th5, Th6, Th7) are respectively equal to $(995,68 \mathrm{MPa}, 754,61 \mathrm{MPa}, 467,09 \mathrm{MPa}, 483,08 \mathrm{MPa}, 369,65 \mathrm{MPa})$ and $(0.29194,0.21719,0.16183,0.21867,0.21867)$ compared to other components of the system spine. We see in Figure 18 the role of the basin to transmit the load to the lower part of the human body and absorbation stresses and strain Von bets (red outline), we note that the two bodies (basin, sacrum) supported stresses and normal elastic deformations which are equal to $(46,069 \mathrm{MPa}, 28,201 \mathrm{MPa})$ and $(0.012947,0.0187)$ relative to the other components of the system of the spine.

\section{Discussion}

In sum, we concluded that the posterior loading is certainly an

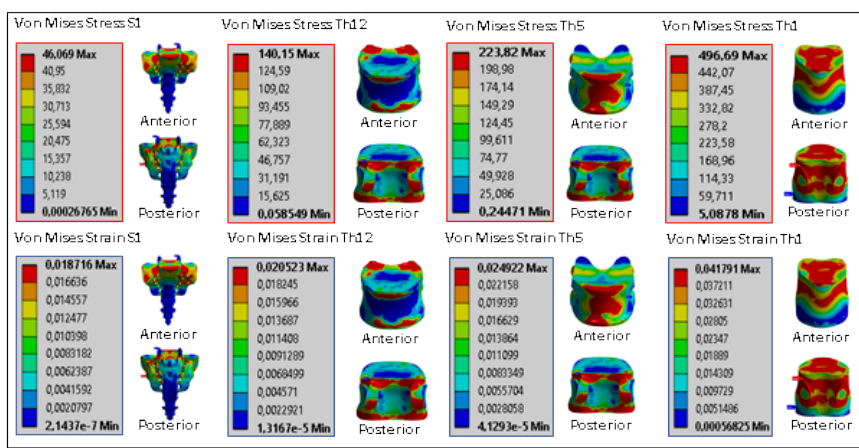

Figure 24. Distributions of stresses and strains in the cortical bone for load of $20 \mathrm{~kg}$.
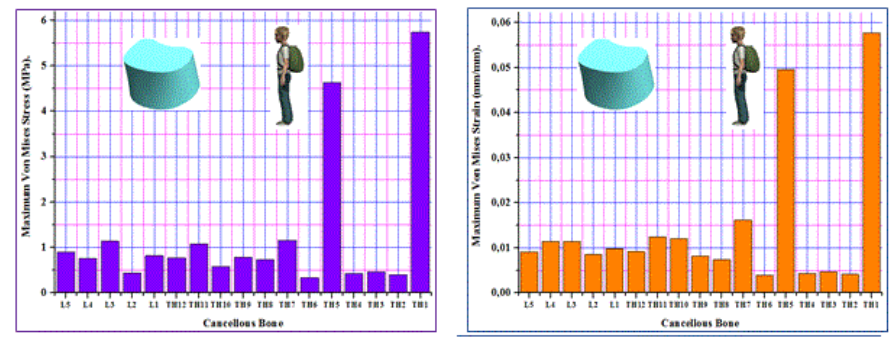

Figure 25. Histogram of stresses and strains in the cancellous bone with a load of $20 \mathrm{~kg}$.

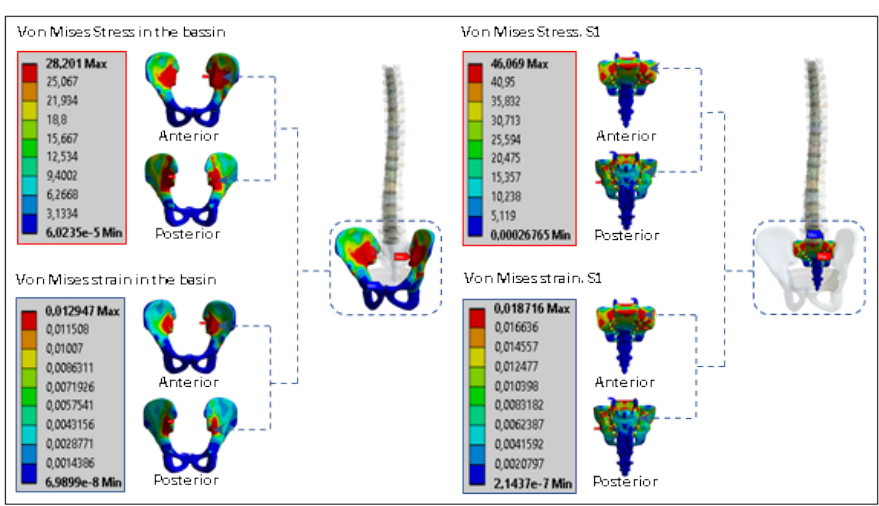

Figure 26. Distributions of stresses and strains in the basin and sacrum for a load of $20 \mathrm{~kg}$. 

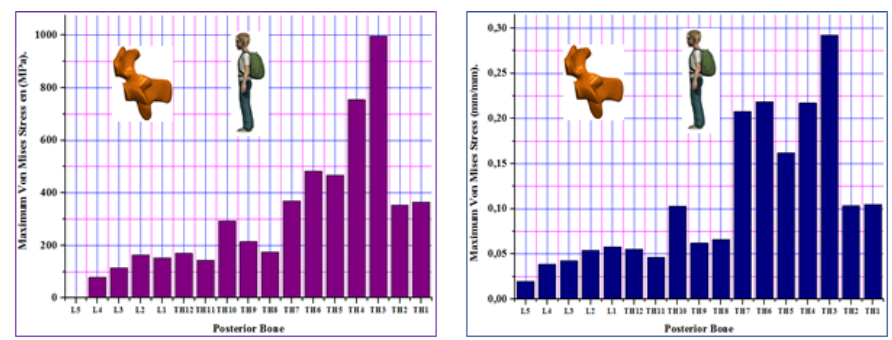

Figure 27. Histogram of stresses and strains in the posterior arch for a load of $20 \mathrm{~kg}$.

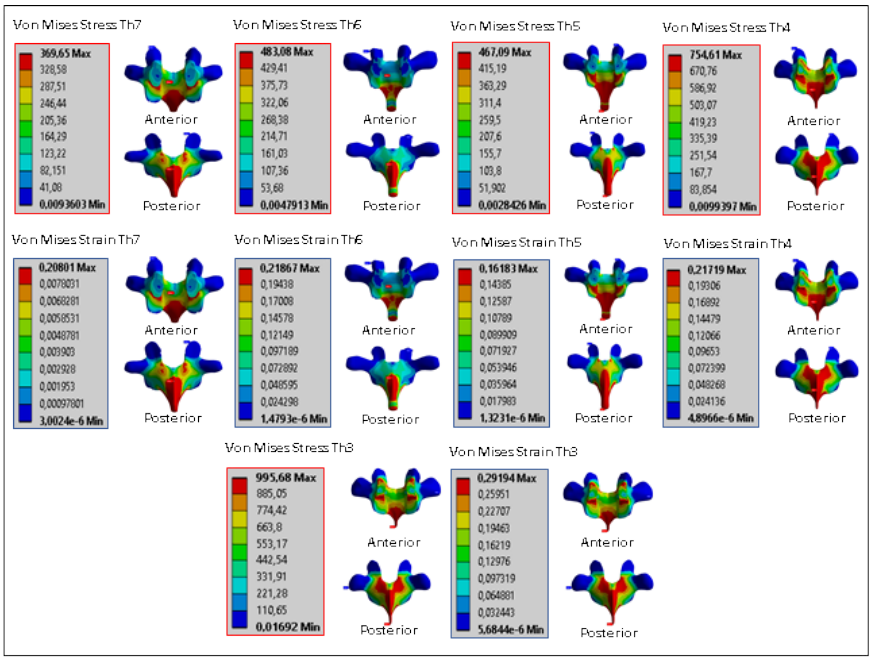

Figure 28. Distributions of stresses and strains in the posterior arch for a load of $20 \mathrm{~kg}$

aggravating factor, and may cause long term back problems and strains of the spine, the 3D model of the spine of a child under the effect of an eccentric load and calculate by the FEM provokes stress and strains maximum of Von Mises concentrated in the intervertebral disc (D1) and are equal to $(6,9797 \mathrm{MPa}, 1,7347 \mathrm{~mm} / \mathrm{mm})$ as noted in the Figure 18 with regard to Figure 19-21 show that the intervertebral disc (D1) is the most damaged which is disc degeneration often occurs after a phase asymptomatic dehydration cracks, tearing of annulus fibrosus (D1), the nucleus (N1) can then along these cracks migrate into the ring thickness (D1), and cause acute or chronic back pain, If the core (N1) move around more through the ring (D1), the core can project to the posterior surface of the disc while forming a lumbar disc herniation, this hernia can complete rupture of the ring, migrate laterally into the vertebral canal, or up or down, and even exclude leaving the disk, herniated disc that can come be compressed one or more nerve roots "stuck" near the disc, causing the symptoms of pain "sciatica" when the rear seat of the thigh or "cruralgie" when the seat of pain in the front of the thigh. This justifies that the distance between the load which is the point of application of the load and the axis of the spine plays an important role in increasing stresses at the intervertebral discs.

\section{Conclusion}

In sum, we concluded the case of posterior loading $350 \mathrm{~mm}$ lever arm with a load $200 \mathrm{~N}$ posterior indicate normal maximum Von Mises stresses in four intervertebral discs (D1, D15, D16, D17) and are equal to $(6,9797 \mathrm{MPa}, 4,4374 \mathrm{MPa}, 4,7858 \mathrm{MPa}, 2,7365 \mathrm{MPa})$ these mentioned in Figure 18 on the other hand Figure 19clearly shows the elastic strain is higher in the four intervertebral discs (D1, D15, D16, D17) that are equal $(1.7347,1.0586,1.1463,066065)$, which justifies that the distance between the load which is the point of application of the load and the axis of the spine plays a very important role in increasing the solitation of the latter.

\section{Acknowledgements}

The authors extend their appreciation to the Director of Scientific Research at LaBPS for funding the work through the Biomechanics Research Group.

\section{References}

1. Thomas M (2008) Contribution A L'analyse Biomécanique Et a L'évaluation des Implants Rachidiens, L'école Nationale Supérieure D'arts Et Métiers Spécialité. Biomécanique, Paris.

2. Hernie Discale Lombaire (2008) Service de Chirurgie orthopédique et Traumatologique, Hôpital Beaujon.

3. Robert Bohinski MD (2016) Herniated Lumbar Disc. Mayfield Clinic, universty of cincinnati department of neurosurgery, cincinnati, Ohio, mayfieled brain and spine.

4. Dr. Kilcup (2011) Herniated disk fixed without harmful. Addictive Drugs and Surgery.

5. Karine L (2014) Institut Français D'étiopathie (IFE) Paris.

6. Kassab M (2016) Centre Avicenne Médical, 2 Av Tahar Sfar, 2092, El Manar 2, Tunis, Tunisie.

7. White Iii AA, Panjabi MM (1990) Clinical Biomechanics of The Spine. ISBN397.

8. Champain SM (2008) Corrélations Entre Les Paramètres Biomécaniques Du Rachis Et Les Indices Cliniques Pour L'analyse Quantitative Des Pathologies Du Rachis Lombaire Et De Leur Traitement Chirurgical, Enam, Paris.

9. Francois L (1997) Biomécanique Et Ostéosynthèse Du Rachis Ensm-Lbm Conférences D'enseignement De La Sofcot.

10. Meijer HJ, Starmans FJ, Steen WH, Bosman F (1993) A three-dimensional, finiteelement analysis of bone around dental implants in an edentulous human mandible. Arch Oral Biol 38: 491-496.[Crossref]

11. Ibarz E, Más Y, Mateo J, Lobo-Escolar A, Herrera A, et al. (2013) Instability of The Lumbar Spine Due To Disc Degeneration. A Finite Element Simulation. Advances in Bioscience and Biotechnology4: 548-556.

12. Mingzhi S, Zhen Z, Ming L, Junwei Z, Chao D, et al. Four Lateral Mass Screw Fixation Techniques In Lower Cervical Spine Following Laminectomy. A finite Element Analysis Study of Stress Distribution. Biomed Eng Online 13:115.

13. Steven A, Rundell MS, Jorge E, Isaza MD, Steven M, et al. (2011)Biomechanica Evaluation ofa Spherical Lumbar Interbody Device at Varying Levels of subsidence. SAS J 5: 16-25.

14. Vijay GK, Ankit BSJ, Jayant BS, Faizan A, Ali MS, et al. (2007) Anatomic facet replacement system (AFRS) restoration of lumbar segment mechanics to intact. a finite element study and in vitro cadaver investigation. SAS Journal1: 46-54.

15. Holekamp S, Goel V, Kuroki H, Huntzinger J, Ebraheim N (2007) Optimal intervertebral sealant properties for the lumbar spinal disc: a finite-element study. $S A S$ $J 1:$ 68-73.[Crossref]

16. Castellvi AE, Huang H, Vestgaarden T, Saigal S, Clabeaux DH, et al. (2007) Stress Reduction in Adjacent Level Discs via Dynamic Instrumentation: A Finite Element Analysis. $S A S$ J1: 74-81.[Crossref]

17. López E, Elena I, Herrera A, Mateo J, Lobo-Escolar A, et al. (2014) Probability of Osteoporotic Vertebral Fractures Assessment Based on DXA Measurements and Finite Element Simulation. Advances in Bioscience and Biotechnology5: 527-545.

18. Kiapour A, Kiapour AM, Kodigudla M, Hill GM, Mishra S, et al. (2012) A Biomechanical Finite Element Study of Subsidence and Migration Tendencies in Stand-Alone Fusion Procedures. Comparison of an In Situ Expandable Device with a Rigid Device. J Spine 1: 2165-7939.

19. Zheng SN, Yao QQ, Wang LM, Hu WH, Wei B, et al. (2013) Biomechanical Effects of Semi Constrained Integrated Artificial Discs on Zygapophysial Joints of Implanted Lumbar Segments. Experimental and Therapeutic Medicine6: 1423-1430.

20. Byun DH, Shin DA, Kim JM, Kim SH, Kim HI (2012) Finite element analysis of the biomechanical effect of coflexa on the lumbar spine. Korean J Spine 9: 131-136. [Crossref]

21. Lan Ch, Kuo Ch, Chen ChH, Hu HT (2013) Finite element analysis of biomechanica 
behavior of whole thoraco-lumbar spine with ligamentous effect. The Changhua Journal of Medicine 11: 26-41.

22. Natarajan RN and Andersson GBJ (1997) Modeling the annular incision in a herniated lumbar intervertebral disc to study its effect on disc stability. Comput Struct64: 12911297.

23. Pitzen T, Geisler FH, Matthis D, Müller-Storz H, Pedersen K, et al. (2001) The influence of cancellous bone density on load sharing in human lumbar spine: a comparison between an intact and a surgically altered motion segment. Eur Spine J 10: 23-29. [Crossref]

24. Polikeit A (2002) Finite element analysis of the lumbar spine: Clinical application. Inaugural dissertation. University of Bern. Advances in Bioscience and Biotechnology 6:8.

25. Denozi Ere G (2004) Numerical modelling of a ligamentous lumber motion segment. M.S. thesis, Department of Mechanical Engineering, Georgia Institute of Technology. Georgia. USA.

26. Gwanseob Shin (2005) Viscoelastic responses of the lumbar spine during prolonged stooping. Ph.D. dissertation, NCSU, USA

27. Sairyo K, Goel VK, Masuda A, Vishnubhotla S, Faizan A, et al. (2006) Threedimensional finite element analysis of the pediatric lumbar spine. Eur Spine J15: 923929.

28. Rohlmann A, Burra NK, Zander T, Bergmann G (2007) Comparison of the effects of bilateral posterior dynamic and rigid fixation devices on the loads in the lumbar spine: a finite element analysis. Eur Spine J16: 1223-1231.[Crossref]

29. Wilke HJ, Neef P, Caimi M, Hoogland T, Claes LE (1999) New in vivo measurements of pressures in the intervertebral disc in daily life. Spine (Phila Pa 1976) 24: 755-762. [Crossref]
30. Smit TH, Odgaard A, Schneider E (1997) Structure and function of vertebral trabecular bone. Spine (Phila Pa 1976)22: 2823-2833.[Crossref]

31. Sharma M, Langrana NA, Rodriguez J (1995) Role of ligaments and facets in lumbar spinal stability. Spine (Phila Pa 1976) 20: 887-900.[Crossref]

32. Lee KK, Teo EC (2004) Effects of laminectomy and facetectomy on the stability of the lumbar motion segment. Med Eng Phys 26: 183-192.[Crossref]

33. Rohlmann A, Zander T, Schmidt H, Wilke Hj, Bergmann G (2006) Analysis of the influence of disc degeneration on the mechanical behaviour of a lumbar motion segment using the finite element method. J Biomech39: 2484-90.

34. Ng HW, Teo EC (2001) Nonlinear finite-element analysis of the lower cervical spine (C4-C6) under axial loading. J Spinal Disord 14: 201-210.[Crossref]

35. Ng HW, Teo ECh, Zhang QH (2004) Influence Of Laminotomies And Laminectomies On Cervical Spine Biomechanics Under Combined Flexion-Extension. Journal of Applied Biomechanics20: 243-259.

36. Gong Z, Chen Z, Feng Z, Cao Y, Jiang C, et al. (2014) Finite element analysis of 3 posterior fixation techniques in the lumbar spine. Orthopedics37: e441-448.[Crossref]

37. Kim HJ, Tak Kang K, Chang BS, Lee ChK, Kim JW, et al. (2014) Biomechanical Analysis of Fusion Segment Rigidity Upon Stress at Both the Fusion and Adjacent Segments-A Comparison between Unilateral and Bilateral Pedicle Screw Fixation. Yonsei Med J55: 1386-1394.

38. Claire BR, Jean PA, Rohan-Jean B, Yves G-R, MEng LF, et al. (2016) Finite Element Analysis of Sacroiliac Joint Fixation under Compression Loads. International Journal of Spine Surgery.

Copyright: (C2016 Zahaf S. This is an open-access article distributed under the terms of the Creative Commons Attribution License, which permits unrestricted use, distribution, and reproduction in any medium, provided the original author and source are credited. 